\title{
Stable Sr isotopes of the Middle-Late Permian carbonate: its implication for driving ocean Sr budget change
}

\author{
TOMOMI KANI ${ }^{1}$, YUKIO ISOZAKI ${ }^{2}$, KEIJI MISAWA ${ }^{3}$, \\ AKIRA ISHIKAWA ${ }^{4}$, SHIGEKAZU YONEDA $^{5}$ \\ ${ }^{1}$ Kumamoto University, Kumamoto, Japan; ${ }^{2}$ The University \\ of Tokyo, Japan; ${ }^{3}$ National Institute of Polar Research, \\ Tachikawa, Japan; ${ }^{4}$ Tokyo Institute of Technology, Japan; \\ ${ }^{5}$ National Museum of Nature and Science, Tsukuba, Japan
}

Stable and radiogenic isotopic composition of $\mathrm{Sr}\left({ }^{87} \mathrm{Sr} /{ }^{86} \mathrm{Sr}\right.$, $\delta^{88} \mathrm{Sr}$ ) of paleoseawater, which are archived in carbonates, can be valid proxies for global change accompanied with ocean $\mathrm{Sr}$ budget [1]. We present $\delta^{88} \mathrm{Sr}$ of oceanic carbonates by double-spike thermal ionization mass-spectrometry (DSTIMS) for the Middle-Late Permian boundary interval with one of the major extinction events. Analyzed carbonate samples include shallow marine carbonates of shelf facies from South China and of mid-Panthalassan palaeo-atoll facies in Japan. Previous studies confirmed the lowest ${ }^{87} \mathrm{Sr} /{ }^{86} \mathrm{Sr}$ value in late Middle Permian followed by drastic increase during the Late Permian to Early Triassic [2]. Likewise, the $\delta^{88} \mathrm{Sr}$ values of the analyzed samples demonstrated low values in Middle Permian and increase during the Late Permian. The low $\delta^{88} \mathrm{Sr}$ values in the Middle Permian indicate the enhanced carbonate weathering, and this may suggest the suppression of reef building under the global cooling recorded in the significant sea level drop.

[1] Vollstaedt et al., 2014, GCA; [2] Korte et al., 2006, PALAEO 